Kansas State University Libraries

New Prairie Press

\title{
STEP-STRESS TESTING IN AGRICULTIJRE
}

Imad H. Khamis

James J. Higgins

Follow this and additional works at: https://newprairiepress.org/agstatconference

Part of the Agriculture Commons, and the Applied Statistics Commons

\section{(c) (i) $\odot$}

This work is licensed under a Creative Commons Attribution-Noncommercial-No Derivative Works 4.0 License.

\section{Recommended Citation}

Khamis, Imad H. and Higgins, James J. (1995). "STEP-STRESS TESTING IN AGRICULTIJRE," Conference on Applied Statistics in Agriculture. https://doi.org/10.4148/2475-7772.1341

This is brought to you for free and open access by the Conferences at New Prairie Press. It has been accepted for inclusion in Conference on Applied Statistics in Agriculture by an authorized administrator of New Prairie Press. For more information, please contact cads@k-state.edu. 


\title{
STEP-STRESS TESTING IN AGRICULTURE
}

\author{
Imad H. Khamis and James J. Higgins \\ Kansas State University
}

\begin{abstract}
Step-stress testing has been used for a number years in engineering. An item is placed on test for a specified period of time. If it does not fail in that time, the stress is increased. This process is repeated for a specified number of stress levels until the item fails. In agriculture, animals or plants may be the test items and dosage of a chemical, amount of fertilizer, temperature, etc, the stress variable. In this paper we suggest several potential applications of step-stress testing in agriculture and present inferential procedures for observations that are distributed exponentially.
\end{abstract}

keywords: life testing, exponential distribution, cumulative exposure model

\section{INTRODUCTION}

This paper introduces step-stress testing to the agricultural research community. We begin by reviewing the engineering origins of step-stress testing. This method of testing was developed as a means of quickly estimating the reliability of highly reliable products. An item, say a lightbulb, is tested at some predetermined level of stress, where the stressing variable may be voltage, temperature, or the like. If the item does not fail within a set period of time, the stress is increased. This is repeated for $\mathrm{k}$ increments of stress until the item fails. A model is fit to the time-to-failure data, typically using maximum likelihood methods. The model is then used to predict mean-time-tofailure at the level of stress under which the item will operate in practice or other appropriate times.

Step stress testing differs from the more familiar constant-stress testing in the following way. In constant-stress testing, a predetermined number of items are tested at each level of stress, and each item is subjected to only one level. In step-stress testing, all items start at an initial low stress, and each is moved to a higher level of stress if it does not fail within a predetermined length of time. For instance, in placing 30 lightbulbs on test at three different voltages $(130,140,150)$, a constant-stress design might place 10 lightbulbs at each of three voltages. In step-stress testing, all 30 would start at 130 volts and remain there for a fixed time. Those that do not fail would be moved to 140 volts, and those that do not fail at 140 would be moved to 150 volts.

Step-stress testing assures that all items fail within a reasonable time. As the level of stress increases, the likelihood of failure increases, so that by the time the item reaches the highest level of stress, it is likely to fail soon. By contrast, in constant-stress testing, there may be a percentage of items that do not fail at all, especially at the lower levels of stress, because the items are highly reliable at these levels. When an item does not fail, its time on test is recorded as a censored time. Step-stress testing is preferred to constant-stress testing when information is likely to be lost due to censoring. An important design issue in step-stress testing is to decide how long an item should remain at one stress before being changed to another. This issue is dealt with in 
Bai, Kim, and Lee (1989) and Khamis (1995), but it is not considered here. For a general discussion of accelerated life testing of which step-stress testing is a special case, see Nelson (1990).

\section{EXAMPLES IN AGRICULTURE}

To our knowledge, step-stress testing has not been used in agricultural experimentation. Such testing is potentially useful when a stress variable is applied to a plant, animal, or other experimental unit, and the time to reach an observable endpoint is recorded. If some experimental units are not likely to reach the endpoint within the allotted testing time under a constant-stress test plan, then step-stress testing may be appropriate. Three such situations are suggested below.

Example 1.. A researcher may be interested in modeling the effect of a potentially lethal drug on some physical characteristic of a laboratory animal. Here the stress variable would be drug level and the response would be the time it takes to reach some critical life stage (e.g. time to reach a critically low white blood count or time to death). In constant-stress testing, the animal may not reach the desired critical life stage or death having been administrated just a single level of the drug. Step-stress testing would assure that each animal eventually receives a sufficient level of the drug to bring it to an observable endpoint.

Example 2. Similar to example one, a researcher may be interested in the time it takes a plant to reach a critical life stage or death after it has becn deprived of an essential nutrient. The typical constant-stress experiment would place each plant under just one level of the nutrient. In step-stress testing, the plant would begin at a normal nutrient level, and then receive decreasing amounts of the nutrient in predetermined steps until a critical life stage or death is observed.

Example 3. A veterinarian may be interested in determining the effects of exercise on the time it takes an animal to reach a certain physiological state. In constant-stress testing, cach animal would be placed at single exercise level, and the time it takes to reach the desired state, if at all, would be recorded. In step-stress testing, the animal would start at a nominal level of exercise, and the level would be increased in predetermined steps until the desired physiological state was reached.

\section{A MATHEMATICAL MODEL FOR STEP-STRESS TESTING}

\section{Notation}

We assume that an experimental unit begins at a low level of stress and then has its stress increased at predetermined times and in predetermined increments until an observable endpoint is reached. The response variable is the time it takes the unit to reach the observable endpoint.

Although not essential for the development, to illustrate the technique we will assume that at each stress the time-to-endpoint has an exponential distribution. Moreover, if $\mathrm{x}$ is the stress variable and $\theta$ is the mean of exponential, we will assume that the log mean time-to-endpoint is linearly related to $\mathrm{x}$. That is, 


$$
\log (\theta)=\beta_{0}+\beta_{1} x
$$

The following notation is used throughout.

$$
\begin{array}{ll}
\mathrm{x}_{1}, \mathrm{x}_{2}, \cdots, \mathrm{x}_{\mathrm{k}} & \text { stress levels }\left(\mathrm{x}_{1}<\mathrm{x}_{2}<\cdots<\mathrm{x}_{\mathrm{k}}\right) \\
\mathrm{n} & \text { total number of units placed on test } \\
\mathrm{n}_{\mathrm{i}} & \text { number of units reaching the endpoint at stress } \mathrm{x}_{\mathrm{i}}, \mathrm{i}=1,2, \cdots, \mathrm{k} \\
\mathrm{T}_{\mathrm{ij}} & \text { time-to-endpoint of test unit } \mathrm{j} \text { at stress } \mathrm{x}_{\mathrm{i}}, \mathrm{i}=1,2, \cdots \mathrm{k}, \mathrm{j}=1,2, \ldots, \mathrm{n}_{\mathrm{i}} \\
\theta_{\mathrm{i}} & \text { mean time-to-endpoint at stress } \mathrm{x}_{\mathrm{i}}, \mathrm{i}=1,2, \cdots, \mathrm{k} . \\
\mathrm{F}_{\mathrm{i}} & \text { cdf of time-to-endpoint of a test unit under stress } \mathrm{x}_{\mathrm{i}}, \mathrm{i}=1,2, \ldots \mathrm{k} . \\
\mathrm{F} & \text { cdf of time-to-endpoint of a test unit under step-stress testing } \\
\tau_{\mathrm{i}} & \text { time at which stress is changed from } \mathrm{x}_{\mathrm{i}} \text { to } \mathrm{x}_{\mathrm{i}+1}, \mathrm{i}=1,2, \cdots, \mathrm{k}-1 .
\end{array}
$$

\section{Procedure for Data Collection}

All $n$ test units are initially placed at low stress $x_{1}$ and run until time $\tau_{1}$ when the stress is changed to $x_{2}$. The test is continued until time $\tau_{2}$ when the stress is changed to $x_{3}$ and so on until time $\tau_{k-1}$ when the stress is changed to $x_{k}$ where testing is continued until all remaining units reach the observable endpoint. We assume that a random number of units $n_{i}$ reach the observed endpoint at stress $\mathrm{x}_{\mathrm{i}}, \mathrm{i}=1,2, \cdots, \mathrm{k}$ and the times-to-endpoint $\mathrm{T}_{\mathrm{ij}}, \mathrm{j}=1,2, \ldots, \mathrm{n}_{\mathrm{i}}$, are observed on these units.

\section{Cumulative Exposure Model}

The model we use is termed the cumulative exposure model by Nelson (1990). The cumulative distribution function, cdf, of the time-to-endpoint $\mathrm{T}$ is a composite of cdfs, where each individual cdf characterizes the distribution of the time-to-endpoint of an item placed on test at a fixed stress. It is given by

$$
\mathrm{F}(\mathrm{t})=\left\{\begin{array}{lc}
\mathrm{F}_{1}(\mathrm{t}) & 0 \leq \mathrm{t}<\tau_{1} \\
\mathrm{~F}_{2}\left(\mathrm{t}-\tau_{1}+\mathrm{s}_{1}\right) & \tau_{1} \leq \mathrm{t}<\tau_{2} \\
\mathrm{~F}_{3}\left(\mathrm{t}-\tau_{2}+\mathrm{s}_{2}\right) & \tau_{2} \leq \mathrm{t}<\tau_{3} \\
\quad \vdots & \vdots \\
\mathrm{F}_{\mathrm{k}}\left(\mathrm{t}-\tau_{\mathrm{k}-1}+\mathrm{s}_{\mathrm{k}-1}\right) & \tau_{\mathrm{k}-1} \leq \mathrm{t}<\infty
\end{array}\right.
$$

where $s_{1}$ is the solution of $F_{2}\left(s_{1}\right)=F_{1}\left(\tau_{1}\right)$, s $s_{2}$ is the solution of $F_{3}\left(s_{2}\right)=F_{2}\left(\tau_{2}-\tau_{1}+s_{1}\right)$ and so on until the $k$ th step where $F_{k}(t)=F_{k-1}\left(\tau_{k-1}-\tau_{k-2}+s_{k-2}\right)$. Using the exponential assumption the likelihood function for observations $T_{i j}=t_{i j}, i=1,2 \ldots, k, j=1,2 \ldots, n_{i}$ is: 


$$
\begin{aligned}
& L\left(\beta_{o}, \beta_{1}\right)=\prod_{j=1}^{n_{1}}\left[\left(\frac{1}{\theta_{1}}\right) \exp \left(-\frac{t_{1 j}}{\theta_{1}}\right)\right] \prod_{j=1}^{n_{2}}\left[\left(\frac{1}{\theta_{2}}\right) \exp \left[-\left(\frac{t_{2 j}-\tau_{1}}{\theta_{2}}\right)-\frac{\tau_{1}}{\theta_{1}}\right] \cdots\right. \\
& \cdots \\
& \prod_{j=1}^{n_{k}} \frac{1}{\theta_{k}} \exp \left[-\left(\frac{t_{k j}-\tau_{k-1}}{\theta_{k}}\right)-\left(\frac{\tau_{k-1}-\tau_{k-2}}{\theta_{k-1}}\right)-\left(\frac{\tau_{k-2}-\tau_{k-3}}{\theta_{k-2}}\right)-\cdots-\left(\frac{\tau_{2}-\tau_{1}}{\theta_{2}}\right)-\frac{\tau_{1}}{\theta_{1}}\right)
\end{aligned}
$$

where $\mathrm{n}=\mathrm{n}_{1}+\mathrm{n}_{2}+\mathrm{n}_{3}+\cdots+\mathrm{n}_{\mathrm{k}}$ and $\log \left(\theta_{\mathrm{i}}\right)=\beta_{\mathrm{o}}+\beta_{\mathrm{l}} \mathrm{x}_{\mathrm{i}}$.

Substituting for $\theta_{i}, i=1,2, \cdots, k$, we find the log likelihood function as a function of unknown parameters $\beta_{0}$ and $\beta_{1}$. That is,

$$
\log L\left(\beta_{o}, \beta_{1}\right)=-n \beta_{o}-\sum_{i=1}^{k} n_{i} x_{i} \beta_{1}-\sum_{i=1}^{k} U_{i} \exp \left(-\beta_{o}-\beta_{1} x_{i}\right)
$$

where

$$
\begin{gathered}
\mathrm{U}_{1} \equiv \sum_{\mathrm{j}=1}^{\mathrm{n}_{1}} \mathrm{t}_{1 \mathrm{j}}+\left(\mathrm{n}_{2}+\mathrm{n}_{3}+\cdots+\mathrm{n}_{\mathrm{k}}\right) \tau_{1}, \\
\mathrm{U}_{2} \equiv \sum_{\mathrm{j}=1}^{\mathrm{n}_{2}}\left(\mathrm{t}_{2 \mathrm{j}}-\tau_{1}\right)+\left(\mathrm{n}_{3}+\mathrm{n}_{4}+\cdots+\mathrm{n}_{\mathrm{k}}\right)\left(\tau_{2}-\tau_{1}\right), \\
\mathrm{U}_{3} \equiv \sum_{\mathrm{j}=1}^{\mathrm{n}_{3}}\left(\mathrm{t}_{3 \mathrm{j}}-\tau_{2}\right)+\left(\mathrm{n}_{4}+\mathrm{n}_{5}+\cdots \mathrm{n}_{\mathrm{k}}\right)\left(\tau_{3}-\tau_{2}\right) . \\
\vdots \\
\mathrm{U}_{\mathrm{k}} \equiv \sum_{\mathrm{j}=1}^{\mathrm{n}_{\mathrm{k}}}\left(\mathrm{t}_{\mathrm{kj}}-\tau_{\mathrm{k}-1}\right)
\end{gathered}
$$

Note that $\mathrm{U}_{\mathrm{i}}$ is a total time at stress $\mathrm{x}_{\mathrm{i}}, \mathrm{i}=1,2, \cdots, \mathrm{k}$.

MLEs for the model parameters $\beta_{0}$ and $\beta_{1}$ can be obtained by solving the following equations using the Newton-Raphson procedure. That is, 


$$
\begin{gathered}
\frac{\partial \log L\left(\beta_{o}, \beta_{1}\right)}{\partial \beta_{o}}=-n+\sum_{i=1}^{k} U_{i} \exp \left(-\beta_{o}-\beta_{1} x_{i}\right)=0 \\
\frac{\partial \log \left(\beta_{o}, \beta_{1}\right)}{\partial \beta_{1}}=-\sum_{i=1}^{k} n_{i} x_{i}+\sum_{i=1}^{k} U_{i} \exp \left(-\beta_{o}-\beta_{1} x_{i}\right)=0
\end{gathered}
$$

The Fisher information matrix is obtained by taking the expected values of the second partial and mixed partial derivatives of $\log L\left(\beta_{0}, \beta_{1}\right)$ with respect to $\beta_{0}$ and $\beta_{1}$. We find

$$
F=n\left[\begin{array}{ll}
\sum_{i=1}^{k} A_{i} & \sum_{i=1}^{k} A_{i} x_{i} \\
\sum_{i=1}^{k} A_{i} x_{i} & \sum_{i=1}^{k} A_{i} x_{i}^{2}
\end{array}\right]
$$

where

$$
\begin{gathered}
A_{1}=1-\exp \left(-\frac{\tau_{1}}{\theta_{1}}\right), \\
A_{2}=\exp \left(-\frac{\tau_{1}}{\theta_{1}}\right)\left[1-\exp \left(-\frac{\left(\tau_{2}-\tau_{1}\right)}{\theta_{2}}\right)\right], \\
A_{3}=\exp \left[-\frac{\left(\tau_{2}-\tau_{1}\right)}{\theta_{2}}-\frac{\tau_{1}}{\theta_{1}}\right]\left[1-\exp -\frac{\left(\tau_{3}-\tau_{2}\right)}{\theta_{3}}\right] \\
\vdots \quad \vdots \\
A_{k}=\exp \left[-\frac{\left(\tau_{k-1}-\tau_{k-2}\right)}{\theta_{k-1}}-\frac{\left(\tau_{k-2}-\tau_{k-3}\right)}{\theta_{k-2}}-\ldots-\frac{\left(\tau_{2}-\tau_{1}\right)}{\theta_{2}}-\frac{\tau_{1}}{\theta_{1}}\right]
\end{gathered}
$$

Note that $A_{i}$ is the probability that a test unit fails while testing at stress $x_{i}$ and $A_{1}+A_{2}+A_{3}+\cdots$ $+\mathrm{A}_{\mathrm{k}}=1$.

The variance-covariance matrix is the inverse of Fisher information matrix. That is 


$$
F^{-1}=\frac{1}{n\left[\sum_{i=1}^{k} A_{i} x_{i}^{2}-\left(\sum_{i=1}^{k} A_{i} x_{i}\right)^{2}\right]}\left[\begin{array}{cc}
\sum_{i=1}^{k} A_{i} x_{i}^{2} & -\sum_{i=1}^{k} A_{i} x_{i} \\
-\sum_{i=1}^{k} A_{i} x_{i} & 1
\end{array}\right]
$$

The asymptotic variance of $\log (\theta)$ can be found as follows.

$$
\begin{aligned}
\operatorname{AVR} & =\operatorname{VAR}\left(\hat{\beta}_{\mathrm{o}}\right)+\mathrm{x}^{2} \operatorname{VAR}\left(\hat{\beta}_{1}\right)+2 x \operatorname{COV}\left(\hat{\beta}_{o}, \hat{\beta}_{1}\right) \\
& =\frac{\sum_{\mathrm{i}=1}^{\mathrm{k}} \mathrm{A}_{\mathrm{i}}\left(\mathrm{x}_{\mathrm{i}}-\mathrm{x}_{\mathrm{o}}\right)^{2}}{\sum_{\mathrm{i}<j}^{\mathrm{k}} \mathrm{A}_{\mathrm{i}} \mathrm{A}_{\mathrm{j}}\left(\mathrm{x}_{\mathrm{j}}-\mathrm{x}_{\mathrm{i}}\right)^{2}}
\end{aligned}
$$

\section{CONFIDENCE INTERVALS}

Confidence intervals for $\beta_{0}, \beta_{1}$, and $\log (\theta)$ for a given $\mathrm{x}$ can be obtained by using the approximate normality of maximum likelihood estimates. That is, we use the approximation

$$
\left(\hat{\beta}_{0}, \hat{\beta}_{1}\right) \sim N\left[\left(\hat{\beta}_{0}, \hat{\beta}_{1}\right), F^{-1}\right]
$$

The confidence intervals for the parameters are

$$
\hat{\beta}_{\mathrm{i}} \pm \mathrm{Z}_{\frac{\alpha}{2}} \sqrt{\mathrm{F}_{\mathrm{ii}}^{-1}}
$$

The confidence interval for $\log (\theta)$ is

$$
\log (\hat{\theta}) \pm \mathrm{Z}_{\frac{\alpha}{2}} \sqrt{\mathrm{AVR}}
$$




\section{Numerical Example}

Suppose a researcher is interested in the potential toxic effect of a herbicide on strawberry plants, and the number of applications of the herbicide is the stress variable of interest. Assume that the levels are 1, 2 or 3 applications. In constant-stress testing, some plants would receive 1 application, some 2, and the remaining 3. In step-stress testing, all begin with 1 application. Those that do not reach the endpoint in a predetermined time would be given the second application, and then the third. Now consider a situation in which 1 application is the most important to the researcher. If it takes too long to observe the endpoint on plants that receive just 1 application, step-stress testing allows the researcher to accelerate the testing by going to 2 and 3 applications. The statistical model provides a way to use all the data to estimate the mean time to reach the endpoint under 1 application.

The statistical parameters of interest are the mean time to reach the endpoint, and the rate at which mean time to endpoint decreases as the number of applications increases. In the notation of the exponential model, the parameters are $\theta$, or equivalently $\log (\theta)$, and $\beta_{1}$. Statistical computations are illustrated below. Since step-stress testing appears not to have been used before in agriculture, the illustration uses simulated data.

The simulated data in Table 1 were generated from the step stress model $\log (\theta)=6-2 \mathrm{x}$ where $\mathrm{x}$ represents three levels of application 1,2, and 3, and the response is time to an observable endpoint such as plant discoloration or death. A simulated test was run under a step-stress plan with $\mathrm{k}=3$ steps and 20 plants. Times to change stresses were chosen so that $25 \%$, on average, reach the observable endpoint before the first change in stress and $75 \%$, on average, reach the observable endpoint before the second change in stress. That is, the values of $\tau_{1}$ and $\tau_{2}$ were chosen for simulation purposes so that $F_{1}\left(\tau_{1}\right)=0.25$ and $F_{2}\left(\tau_{2}-\tau_{1}+s_{1}\right)=0.75$. This choice was made for the sake of illustration. Experience with real data, and optimal design considerations, would dictate the choices in practice.

The maximum likelihood estimates of $\beta_{0}, \beta_{1}$, and $\log (\theta)$ when $x=1$ were found to be 6.00 , -2.11 , and 3.89, respectively. Stresses were changed at $\tau_{1}=15.70$ and $\tau_{2}=23.83$. The estimated variance covariance matrix were found to be

$$
\hat{\mathrm{F}}_{\mathrm{A}}^{-1}=\left[\begin{array}{cc}
0.45 & -0.20 \\
-0.20 & 0.10
\end{array}\right]
$$

The confidence interval for the intercept is

$$
6.00 \pm 1.96 \sqrt{.45}
$$

or 4.69 to 7.31 . The confidence interval for the slope is 


$$
-2.11 \pm 1.96 \sqrt{.10}
$$

or -2.73 to -1.49 . The confidence interval for $\log (\theta)$ when $\mathrm{x}=1$ is

$$
3.89 \pm 1.96 \sqrt{.45+.10-2(.20)}
$$

or 3.13 to 4.65 . A confidence interval for the mean time-to-endpoint when $\mathrm{x}=1$ can be obtained by exponentiating this confidence interval.

If we have two independent samples from treatments $\mathrm{A}$ and $\mathrm{B}$, then confidence intervals can be obtained for differences in parameters. These would be obtained as

$$
\left(\hat{\beta}_{\mathrm{iA}}-\hat{\beta}_{\mathrm{iB}}\right) \pm \mathrm{z}_{\left(\frac{\alpha}{2}\right)} \sqrt{\operatorname{VAR}\left(\hat{\beta}_{\mathrm{iA}}\right)+\operatorname{VAR}\left(\hat{\beta}_{\mathrm{iB}}\right)}
$$

The confidence interval for the difference between the log means at a selected value of $\mathrm{x}$ would be obtained as

$$
\left[\log \left(\hat{\theta}_{\mathrm{A}}\right)-\log \left(\hat{\theta}_{\mathrm{B}}\right)\right] \pm \mathrm{Z}_{\left(\frac{\alpha}{2}\right)} \sqrt{\mathrm{AVR}_{\mathrm{A}}+\mathrm{AVR}_{\mathrm{B}}}
$$

Table 1. Simulated Data

\begin{tabular}{||c|llll||}
\hline \hline step stress & \multicolumn{3}{|l||}{ time-to-endpoint } \\
\hline $\mathrm{x}_{1}=1.0$ & 0.19 & 0.89 & 1.47 & 4.66 \\
& 9.34 & & & \\
& & & & \\
$\mathrm{x}_{2}=2.0$ & 15.73 & 15.91 & 16.88 \\
& 16.98 & 17.22 & 17.32 & \\
& 17.70 & 18.73 & 19.89 & 20.23 \\
& & & & \\
& & & & \\
$\mathrm{x}_{3}=3.0$ & & & & \\
& 24.16 & 24.30 & 24.53 \\
& 24.73 & 25.37 & \\
\hline
\end{tabular}




\section{SUMMARY}

Step-stress testing originated in engineering as a means of gathering information quickly on highly reliable items. In agricultural, step-stress testing may prove useful when stresses can be administered to experimental units in increasing increments and time-to-endpoint is a meaningful response variable. It is particularly useful when it takes too long for all experimental units to reach the desired endpoint under low stress. It allows the researcher to obtain complete data on time-to-endpoint without having to extend testing time or running the risk of losing information due to censoring. We have considered step-stress testing assuming simple linear regression and an exponential cumulative exposure model. Khamis (1995) extends these results to the multiple regression and polynomial settings. The standard statistical packages do not have procedures for analysis of step-stress tests, and only a few distributions such as the exponential and Weibull have been considered in the engineering literature. Thus, step-stress testing would appear to be a fruitful area for further development. The ultimate usefulness of step-stress testing will depend on whether the agricultural researcher finds it to be a natural way to conduct certain kinds of experiments.

\section{REFERENCES}

[1] D. S.Bai, M. S. Kim, S. H. Lee, 'Optimum simple step-stress accelerated life tests with censoring', IEEE Trans. Reliability, Vol. 38, no. 5, Dec. 1989 , pp. 528-532.

[2] Khamis, Imad H., 'Multiple Step-Stress Accelerated Life Testing', Ph.D. Dissertation, Dept. of Statistics, Kansas State U., June 1995.

[3] W. Nelson, 'Accelerated testing Statistical Models, Test Plans, and Data Analysis' . Wiley, New York, 1990. 